\title{
Successful treatment of relapsing Pigmented Villonodular Synovitis (PVNS) of the knee with radiosynoviorthesis
}

\author{
C Costantini ${ }^{* 1,2,3,4}$, GF Dalla Pozza ${ }^{1}$, G Bertoni ${ }^{1}$, G Martini ${ }^{1}$ and F Zulian ${ }^{1}$
}

Address: ${ }^{1}$ Paediatric Unit, Treviso, Italy, ${ }^{2}$ Nuclear Medicine Dpt, Treviso, Italy, ${ }^{3}$ Orthopaedic Dpt, Treviso, Italy and ${ }^{4}$ Department of Paediatrics, Padova, Italy

* Corresponding author

from $15^{\text {th }}$ Paediatric Rheumatology European Society (PreS) Congress

London, UK. 14-17 September 2008

Published: 15 September 2008

Pediatric Rheumatology 2008, 6(SuppI I):PI5I doi:I0.II86/I546-0096-6-SI-PI5I

This abstract is available from: http://www.ped-rheum.com/content/6/SI/PI5I

(c) 2008 Costantini et al; licensee BioMed Central Ltd.

PVNS is a rare disorder characterised by benign proliferation of synovial tissue. The treatment is surgical but relapse rate is high ( $8 \%$ to $46 \%$ ). We report a 13 years old girl with PVNS of the left knee diagnosed in February 2003. Three months after diagnosis she underwent surgical synovectomy. Two years later important swelling of left knee with pain and limitation of movement developed and MRI confirmed the relapse of PVNS. She was treated with 3 intraarticular injections of etanercept two months apart with mild reduction of fluid but not of synovial hypertrophy. In November 2006 radiosynoviorthesis with one intraarticular injection of $186 \mathrm{Re}$ was performed. No side effects were reported and patient presented an important reduction of pain and improvement of range of motion. Six months after the procedure MRI showed marked decrease of fluid accumulation, and a mild reduction of synovial hypertrophy. One further intraarticular injection of ${ }^{186} \mathrm{Re}$ has been performed 18 months after the first in order to obtain a more complete effect on synovial thickening.

In our case radiosynoviorthesis has been showed as a safe and effective treatment in relapsing PVNS, which can be considered both as alternative to surgical synovectomy and complementary to it in order to obtain a more persistent remission of the disease. The collaboration between paediatric rheumatologist, nuclear physician and orthopaedic surgeon is fundamental in establishing the timing of the procedure as well as type and dose of radioisotope to be used according to the age of the patient and the PVNS extension. 